\title{
Influence of expanded graphite (EG) and graphene oxide (GO) on physical properties of PET based nanocomposites
}

\author{
Sandra Paszkiewicz ${ }^{*}$, Małgorzata Nachman ${ }^{1}$, Anna Szymczyk ${ }^{2}$, Zdeno Špitalský ${ }^{3}$, \\ Jaroslav Mosnáček ${ }^{4}$, Zbigniew Rosłaniec ${ }^{1}$ \\ ${ }^{1}$ West Pomeranian University of Technology, Szczecin, Institute of Materials Science and Engineering, Piastów Av. 19, \\ 70-310 Szczecin, Poland \\ ${ }^{2}$ West Pomeranian University of Technology, Szczecin, Department of Chemical Engineering \\ ${ }^{3}$ Slovak Academy of Sciences, Polymer Institute, Dúbravská cesta 9, 84541 Bratislava 45, Slovakia, \\ ${ }^{4}$ Slovak Academy of Sciences, Polymer Institute, Centre of Excellence FUN-MAT, Dúbravská cesta 9, \\ 84541 Bratislava 45, Slovakia \\ "Corresponding author: e-mail: spaszkiewicz@zut.edu.pl
}

\begin{abstract}
This work is the continuation and refinement of already published communications based on PET/EG nanocomposites prepared by in situ polymerization ${ }^{\mathbf{1 , 2}}$. In this study, nanocomposites based on poly(ethylene terephthalate) with expanded graphite were compared to those with functionalized graphite sheets (GO). The results suggest that the degree of dispersion of nanoparticles in the PET matrix has important effect on the structure and physical properties of the nanocomposites. The existence of graphene sheets nanoparticles enhances the crystallization rate of PET. It has been confirmed that in situ polymerization is the effective method for preparation nanocomposites which can avoid the agglomeration of nanoparticles in polymer matrices and improve the interfacial interaction between nanofiller and polymer matrix. The obtained results have shown also that due to the presence of functional groups on GO surface the interactions with PET matrix can be stronger than in the case of exfoliated graphene (EG) and matrix.
\end{abstract}

Keywords: in situ polymerization, PET, graphene oxide, expanded graphite.

\section{INTRODUCTION}

One of the most widely used semi-crystalline polyesters in the world is poly(ethylene terephthalate) (PET) as a thermoplastic polymer material. For some time now, PET has expanded its applications in a variety of fields, ranging from fibers to films and magnetic recording tape substrates ${ }^{3,4}$. Although PET has balanced properties of mechanical strength, thermal property, and barrier property for commodity and engineering applications, the further improvement in thermal and mechanical properties of PET is needed to pursue for high performance applications.

Incorporation of nanofillers in a polymer matrix gives rise to a new class of materials known as polymer nanocomposites, which have better potential for many applications. Polymeric nanocomposites have been a topic of great interest for the last two decades for scientists all over the world. Numerous researchers have already reported the effect of different nanofillers like clay, carbon nanotubes, graphene and graphene derivatives and silica on polymer properties ${ }^{5-8}$. Development of nanocomposites from various clay, carbon nanotubes and graphene derivatives has been discussed in several publications from our laboratory group ${ }^{1,2,9-11}$. Among those nanofillers, graphene sheet, a 2-dimensional monolayer of $\mathrm{sp}^{2}$-bonded carbon atoms arranged in a honeycomb network, has been recently considered as an ideal reinforcing material to enhance the thermal, mechanical, and electrical performances of polymeric materials due to its outstanding thermal stability, mechanical modulus, and in-plane electrical conductivity ${ }^{12-15}$. Accordingly, PET-based nanocomposites containing graphene sheets have been also prepared and their structures and electrical properties have been investigated ${ }^{16-17}$. However, the influence and comparison of EG and GO on poly(ethylene terephthalate) based nanocomposites prepared by in situ polymerization have not been investigated systematically.

In this work, the influence of expanded graphite (EG) and graphene oxide content on the synthesis process and physical properties of poly(ethylene terephthalate) (PET) is investigated. For this purpose, PET/EG and PET/GO nanocomposites at different nanofiller loadings were prepared by in situ polymerization.

\section{EXPERIMENTAL}

\section{Material}

For the poly(ethylene terephthalate) (PET) synthesis the following chemicals were used: dimethyl tereftalate (DMT) (Sigma-Aldrich); ethane-1,2-diol (Sigma-Aldrich), zinc acetate $\mathrm{Zn}\left(\mathrm{CH}_{3} \mathrm{COO}\right)_{2}$ (Sigma - Aldrich) as an ester exchange catalyst; antimony trioxide $\mathrm{Sb}_{2} \mathrm{O}_{3}$ (SigmaAldrich) as a polycondensation catalyst; Irganox 1010 (Ciba-Geigy, Switzerland) as a thermal stabilizer. EG was prepared by thermal expansion (SGL Carbon SE, Germany); average thickness of the expanded agglomerates was 450-560 $\mathrm{nm}$. Graphene platelets size ranged from $16 \mu \mathrm{m}$ to $46 \mu \mathrm{m}(99 \%)$. Graphite oxide (GO) with flake size of about $5 \mu \mathrm{m}$ was provided by Polymer Institute of Slovak Academy of Sciences, where the natural graphite was first converted to intercalated or expandable graphite through chemical oxidation in the presence of concentrated $\mathrm{H}_{2} \mathrm{SO}_{4}$ and $\mathrm{HNO}_{3}$ acids. Before adding nanofillers to the reaction mixture they were combined with ethanediol in order to split agglomerates and to improve further exfoliation. Polymer nanocomposites PET/EG and PET/GO have been synthesized following the same procedure ${ }^{1}$. 


\section{Preparation of PET/EG and PET/GO nanocomposites}

Nanocomposites based on poly(ethylene terephthalate) (PET) were prepared by in situ polymerization in the polycondensation reactor (Autoclave Engineers, Pennsylvania, USA) capacity of $1000 \mathrm{~cm}^{3}$.The process was conducted in two stages, followed the same procedure as published elsewhere ${ }^{\mathbf{1}, 2,10}$. In the first stage, at atmospheric pressure and temperature range of $175 \div$ $190^{\circ} \mathrm{C}$, took place transesterification reaction between both dimethyl terephthalate (DMT) and ethylene glycol with the addition of nanofiller (EG, GO), which was initially dispersed using high-speed stirrer (Ultra-Turax T25), sonicator (Homogenizer HD 2200, Sonoplus) and ultra-power lower sonic bath (BANDELIN, Sonorex digitec), resulting in the precipitation of methanol. When a precipitated amount of alcohol was close to the theoretical amount, the pressure was gradually lowered to about $0.1 \mathrm{hPa}$ and the second stage was begun. Polycondensation carried in temperature to $275^{\circ} \mathrm{C}$ by the stirrer speed $40 \mathrm{rot} / \mathrm{min}$. The progress of this step of reaction was monitored based on observations of the changing viscosity of the reaction mixture, which was in turn monitored on the basis of observations of changes in torque stirrer during the synthesis. The reaction was considered complete when the viscosity in the system rose to $14 \mathrm{~Pa} \cdot \mathrm{s}$. The obtained polymer/nanocomposite was extruded from the reactor at a pressure.

\section{Characterization methods}

The inherent viscosity $[\eta]$ of the polymers was determined at $30^{\circ} \mathrm{C}$ using a capillary Ubbelohde type $I_{\text {c }}(K=0.03294)$, according to the procedure described elsewhere ${ }^{1,2,9-11,18}$. The polymer solution had a concentration of $0.5 \mathrm{~g} / \mathrm{dl}$ in mixture phenol/1,1,2,2-tetrachloroethane $(60 / 40$ by weight). To ensure that the intrinsic viscosity will not be affected by present EG and $\mathrm{GO}$, the polymer nanocomposite solution was filtered through $0.2 \mu \mathrm{m}$ pore size polytetrafluoromethylene (PTFE) filter (Whatman; membrane type TE 35). After filtration the polymer was precipitated and re-dissolved. The Mark-Houwink relationship $[\eta]=372 \cdot 10^{-4} \cdot M^{0.73}$ was used to calculate the viscosity average molar mass of PET homopolymer ${ }^{\mathbf{1 9}}$.

The melt volume rate (MVR) was measured by using a melt indexer (CEAST, Italy) as melt flow in $\mathrm{cm}^{3}$ per $10 \mathrm{~min}$, at temperature of $280^{\circ} \mathrm{C}$, and at orifice diameter $1.050 \mathrm{~mm}$ and under $2.160 \mathrm{~kg}$ load, according to ISO 1133 specification.

The density was measured at $21^{\circ} \mathrm{C}$ on hydrostatic balance (Radwag WPE 600C, Poland), calibrated for standards with known density.

To evaluate the actual amount of nanofiller, the polymer nanocomposites with the nanofiller content of 0.4 wt. $\%$ solution was filtered through $0.2 \mu \mathrm{m}$ pore size polytetrafluoromethylene (PTFE) filter (Whatman; membrane type TE 35). For this purpose, expanded graphite and graphene oxide from the known mass of the nanocomposite have been filtrated. After filtration the polymer was precipitated, re-dissolved and weighted. The PTFE filter, with nanofiller on the surface, after filtration and vacuum drying was also weighted.

The thermal properties of PET based nanocomposites were studied with differential scanning calorimetry (DSC,
TA Instruments Q-100, USA, 2004) in cycle: heating cooling - heating in the temperature range from -50 to $300^{\circ} \mathrm{C}$ at a scan rate of $10^{\circ} \mathrm{C} / \mathrm{min}$. The second heating and cooling scans were used to determine the melting and crystallization peaks. The glass transition temperature $\left(\mathrm{T}_{\mathrm{g}}\right)$ for the prepared nanocomposites and pure PET was taken as the midpoint of the change in heat capacity. The degree of crystallinity ( $X_{c}$, mass fraction) was calculated using the formula:

$X_{c}=\frac{\Delta H_{m}}{\Delta H_{m}^{0}} 100 \%$

where: $\Delta H_{m}$ - enthalpy of melting of the measured sample, $\mathrm{J} / \mathrm{g} ; \Delta H_{m}^{0}=140.01 \mathrm{~J} / \mathrm{g}$ - the theoretical value of enthalpy for $100 \%$ crystalline $\mathrm{PET}^{\mathbf{2 0}}$.

The structure of nanoparticles and nanocomposites were observed by scanning electron microscopy (SEM) (JEOL JSM 6100) and transmission electron microscope (TEM) (JEOL JEM-1200 EX Electron Microscope). The samples were cryofractured in liquid nitrogen, and then vacuum coated with a thin gold film before being analyzed using SEM.

\section{RESULTS AND DISCUSSION}

\section{Morphology and phase structure}

To investigate the dispersion quality of expanded graphite (EG) and graphene oxide (GO) particles, the morphology of PET/EG and PET/GO composites were studied by TEM and SEM and the results are shown in Figure 1. The obtained nanocomposites exhibit a relatively homogenous distribution with highly exfoliated EG and GO in PET matrix. On TEM images the more and less transparent few layer graphene/graphene oxide (Fig. 1a-b) were observed. It can also be seen from Figure 1 that the sizes of both the modified and unmodified graphene sheets are mostly in the range of 5-20 $\mu \mathrm{m}$ except the aggregated sheets, suggesting that in situ polymerization is a effective method for preparing nanocomposites. However, no big difference in the level of filler dispersion/exfoliation was observed on SEM images between GO and EG-filled composites at $0.4 \mathrm{wt} \%$, suggesting that at low loadings the presence of functional groups on the surface of GO does not lead to significant improve exfoliation of GO in PET matrix. However, the observations of more embedded GO platelets (Fig. 1d) in polymer matrix GO can suggest the interactions between functional groups of GO and PET matrix. The presence of functional groups such as carboxylic groups on GO surface can improve interfacial adhesion between graphene and polymer matrix mainly due to the possible interaction of hydrogen bonding between the $\mathrm{COOH}$ groups of GO and the ester groups in polymer matrix. Such behaviour was observed for carboxy-functionalized carbon nanotubes PET, PEN nanocomposites ${ }^{21-22}$. Moreover, the observed also folded/wrinkled surface texture of the few layer graphene/graphene oxide (Fig. 1a-b) can play an important role in enhancing mechanical interlocking and load transfer with the matrix.

\section{Physical properties of nanocomposites}

Values of $[\eta]$ for polymer nanocomposites after nanofiller filtration are varied between 0.49 and $0.55 \mathrm{dl} / \mathrm{g}$ and 
a)

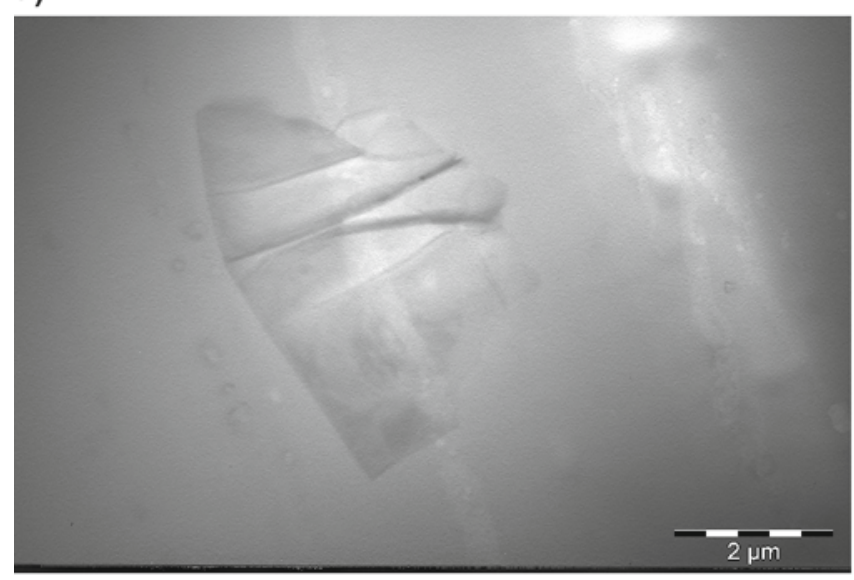

c)

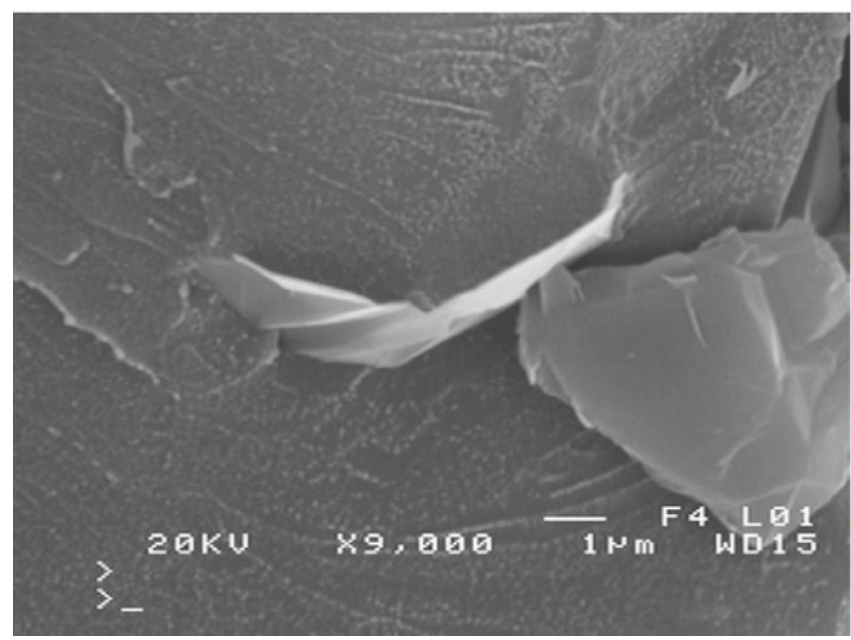

b)

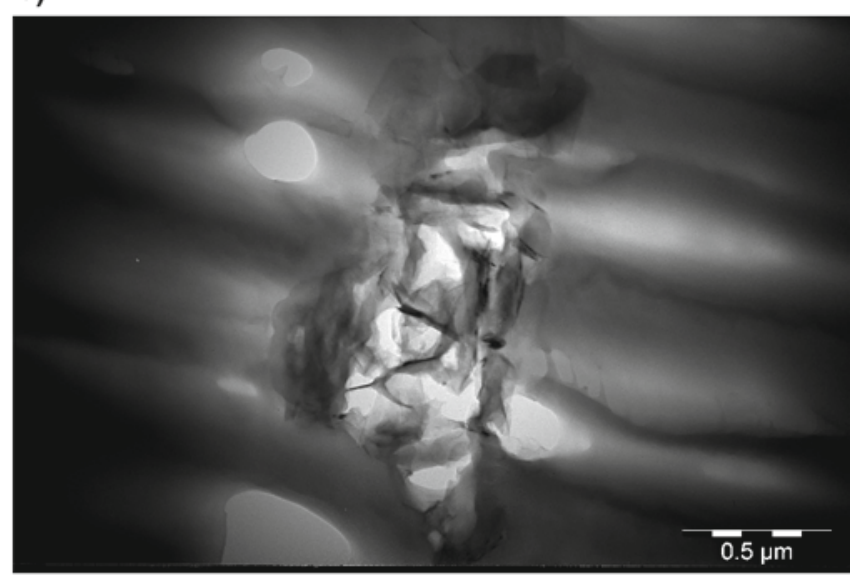

d)

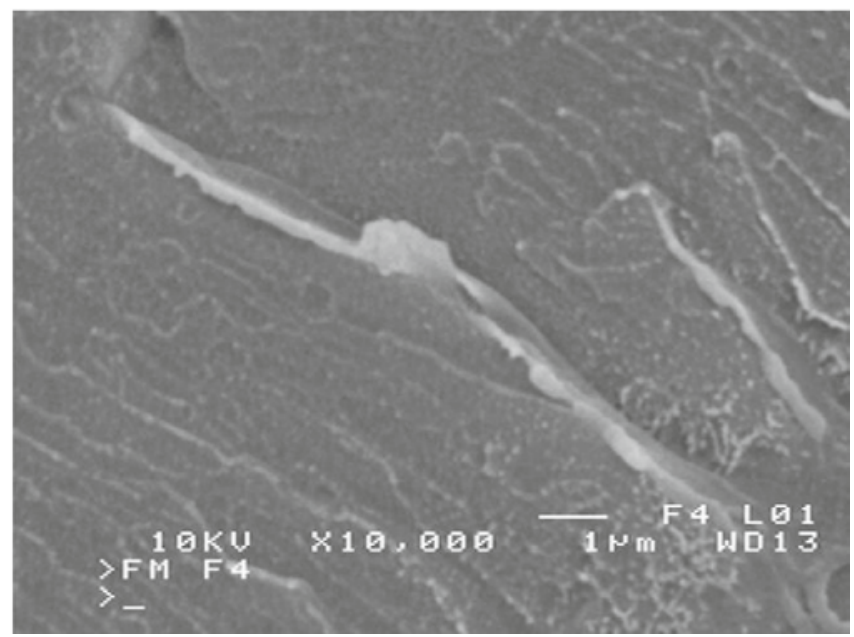

Figure 1. (a-b) TEM micrographs of: (a) PET/0.4EG, 40x, (b) PET/0.4GO, 75x, (c-d) SEM micrographs of: (c) PET/0.4EG, (d) PET/0.4GO

they are close to the value obtained for the neat PET $(0.536 \mathrm{dl} / \mathrm{g})$. As can be seen in Table 1 , the obtained values of $[\eta]$ show that the synthesized nanocomposites have high molecular weights with a slight decrease with the increasing content of both nanofillers (EG and GO) from $2.12 \cdot 10^{4}$ for PET to $1.87 \cdot 10^{4}$ for $\mathrm{PET} / 0.4 \mathrm{GO}$ nanocomposite after nanofiller filtration.

A slight reduce in the MVR only for nanocomposite with 0.1 wt. $\%$ of graphene oxide and no changes for PET/0.4GO was observed. Both nanocomposites, with $0.1 \mathrm{GO}$ and $0.4 \mathrm{GO}$ have similar molecular weights but lower than pure PET. The comparable value of MVR for PET and PET/GO nanocomposites was due to the polymer - functionalized graphene sheets interactions. The presence of EG and GO affects the viscosity of the melt in the synthesis of nanocomposites which reduced the molecular weight of the PET matrix in obtained nanocomposites. Moreover, with the same content (0.1 and $0.4 \mathrm{wt} . \%$ ) of EG and GO nanofillers the differences in their impact on the molecular weight of PET matrix in nanocomposites and the viscosity of the melts was observed. For PET/EG nanocomposites the slight reduction in molecular weight at $0.4 \mathrm{wt} \%$ of $\mathrm{EG}$ content in the composite resulting in reduced melt viscosity (higher values of MVR). The large increase from 72.8 (for pure PET) to $118.9 \mathrm{~cm}^{3} / 10 \mathrm{~min}$ for $\mathrm{PET} / 0.4 \mathrm{EG}$ can be also due to lack of polymer-expanded graphite interactions.

Nanocomposites in comparison to the neat polymer have slightly higher density due to the presence of nanofiller with higher density (Table 1).

The obtained nanocomposites with the highest content of nanofillers ( 0.4 wt.\% of EG and $0.4 \mathrm{wt} \%$ of GO) were tested for the actual content of nanofiller in the, prepared via in situ polymerization, nanocomposites. The subsequent steps of performed experiment are shown in Figure 2. The nanocomposite was dissolved in mixture phenol/1,1,2,2-tetrachloroethane ( $60 / 40$ by weight) in the Erlenmeyer flask (Fig. 2a). After filtration in vacuum,

Table 1. Composition and physical properties of PET/EG and PET/GO nanocomposites

\begin{tabular}{|l|c|c|c|c|c|}
\hline \multicolumn{1}{|c|}{ Sample } & $\begin{array}{c}\text { Nanofiller content } \\
{[\mathrm{wt} \%]}\end{array}$ & $\begin{array}{c}\text { [n] } \\
\text { (For polymer matrix) } \\
{[\mathrm{dL} / \mathrm{g}]}\end{array}$ & $\begin{array}{c}M_{v} \times 10^{4} \\
{[\mathrm{~g} / \mathrm{mol}]}\end{array}$ & $\begin{array}{c}\mathrm{d}_{23} \\
{\left[\mathrm{~g} / \mathrm{cm}^{3}\right]}\end{array}$ & $\begin{array}{c}\text { MVR } \\
{\left[\mathrm{cm}^{3} / 10 \mathrm{~min}\right]}\end{array}$ \\
\hline PET & 0 & 0.536 & 2.12 & 1.330 & $72.8 \pm 1.9$ \\
\hline PET/0.1EG & 0.1 & 0.550 & 2.19 & 1.336 & $87.5 \pm 2.8$ \\
\hline PET/0.4EG & 0.4 & 0.501 & 1.93 & 1.344 & $118.9 \pm 6.8$ \\
\hline PET/0.1GO & 0.1 & 0.490 & 1.87 & 1.338 & $74.5 \pm 7.8$ \\
\hline PET/0.4GO & 0.4 & 0.490 & 1.87 & 1.348 & $72.8 \pm 1.4$ \\
\hline
\end{tabular}

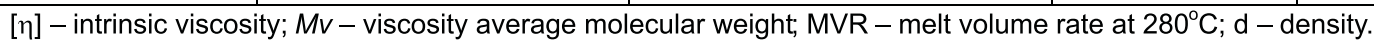


a)

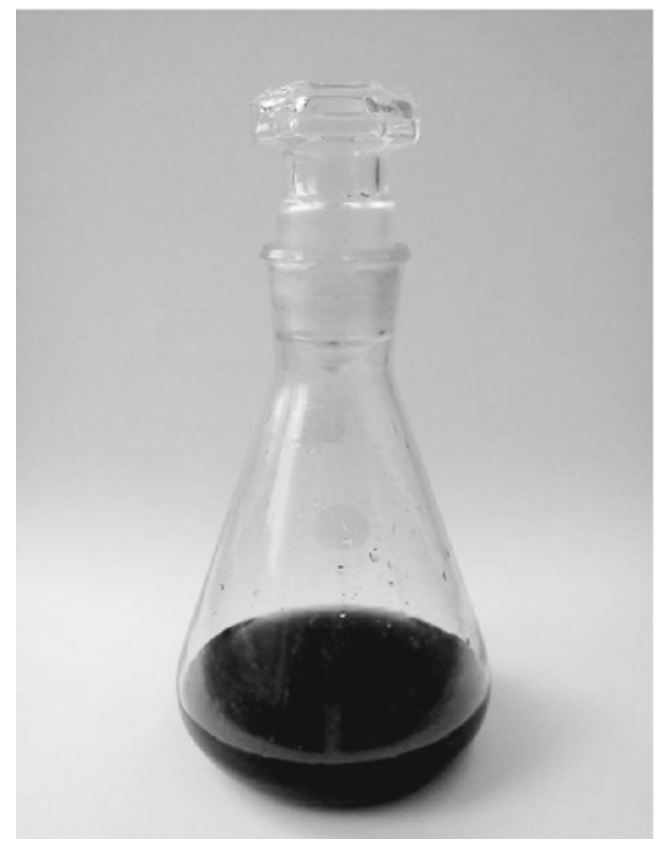

b)

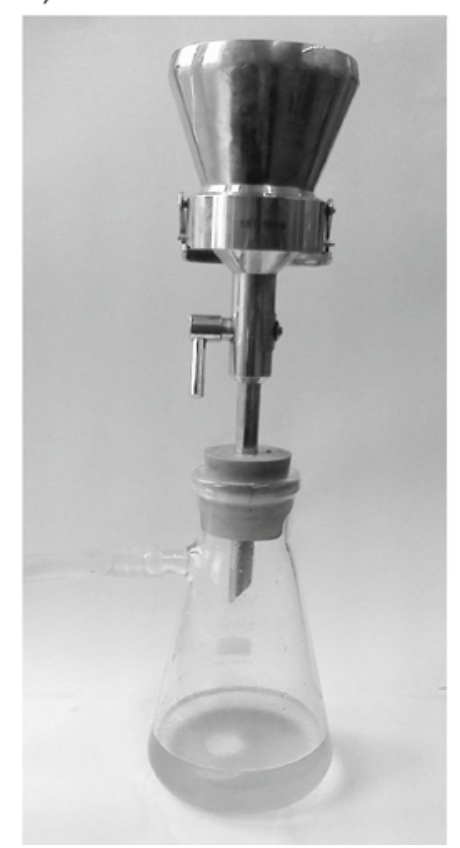

c)

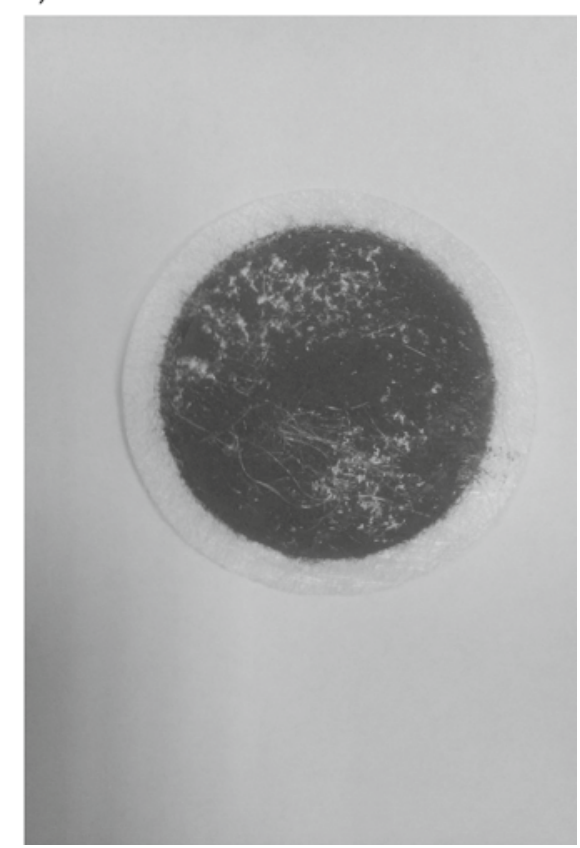

Figure 2. Multi step process of estimation of actual content of nanofiller in prepared via in situ polymerization PET/0.4EG and PET/0.4GO nanocomposites: a) Erlenmeyer flask with nanocomposite solution, b) nanocomposite solution after nanofiller filtration and c) filter with nanofiller

remained nanofiller no longer (Fig. 2b), what confirms the transparent color of the solution. After complete separation of the nanofiller from the nanocomposite the teflon filter has been dried and weighed (Fig. 2c). The conducted experiment confirmed that using in situ polymerization as a method of preparing polymer nanocomposites allows to retain an uniform and quantitative composition in the entire volume of obtained sample in relation to the output composition.

\section{Thermal properties}

The effect of expanded graphite and graphene oxide on the thermal behaviour of the nanocomposites and neat PET during heating and cooling was examined by DSC (Table 2, Fig. 3). As can be seen from the Table 2 , the glass transition temperature was not affected by the presence of EG and GO in polymer matrix. Degrees of crystallinity of the nanocomposites are comparable to those neat PET. The rate of crystallization was shown to depend strongly upon molecular weight ${ }^{23}$. However, the crystallization traces in Figure $2 \mathrm{a}$ indicate that GO worked as a nucleation agent for the crystallization of PET. The lower molecular weights also have the influence on crystallization of PET matrix in prepared nanocomposites, what have been also shown in recent study $^{24}$. At the same cooling rate, the nanocomposites with 0.4 wt. $\%$ of EG and 0.4 wt.\% of GO show higher crystallization temperatures (Fig. 3a, Table 2). The degree of supercooling $\left(\Delta \mathrm{T}=\mathrm{T}_{\mathrm{m}}-\mathrm{T}_{\mathrm{c}}\right)$ may indicate a polymer's crystallizability; that is, the smaller the $\Delta T$, the higher the overall crystallization rate. The $\Delta \mathrm{T}$ values for the nanocomposites are smaller, by $36-38^{\circ} \mathrm{C}$, than that of neat PET $\left(43^{\circ} \mathrm{C}\right)$. Nanofiller usually affect the ability to crystallize semi-crystalline polymers ${ }^{25-27}$. Distributed in the polymer matrix nanoparticles can assist by nucleation and growth of crystallites. Crystallization rate of a polymer is determined by the nucleation rate and mobility of polymer chains. Recent study on crystallization process in
PET modified CNT nanocomposites have shown that the variations of the nucleation activity and the crystallization activation energy of the PET nanocomposites reflected the enhancement of crystallization of the PET nanocomposites effectively induced by a very small quantity of the carboxylic acid groups-induced CNTs (c-CNTs). The incorporation of the c-CNTs into the PET matrix
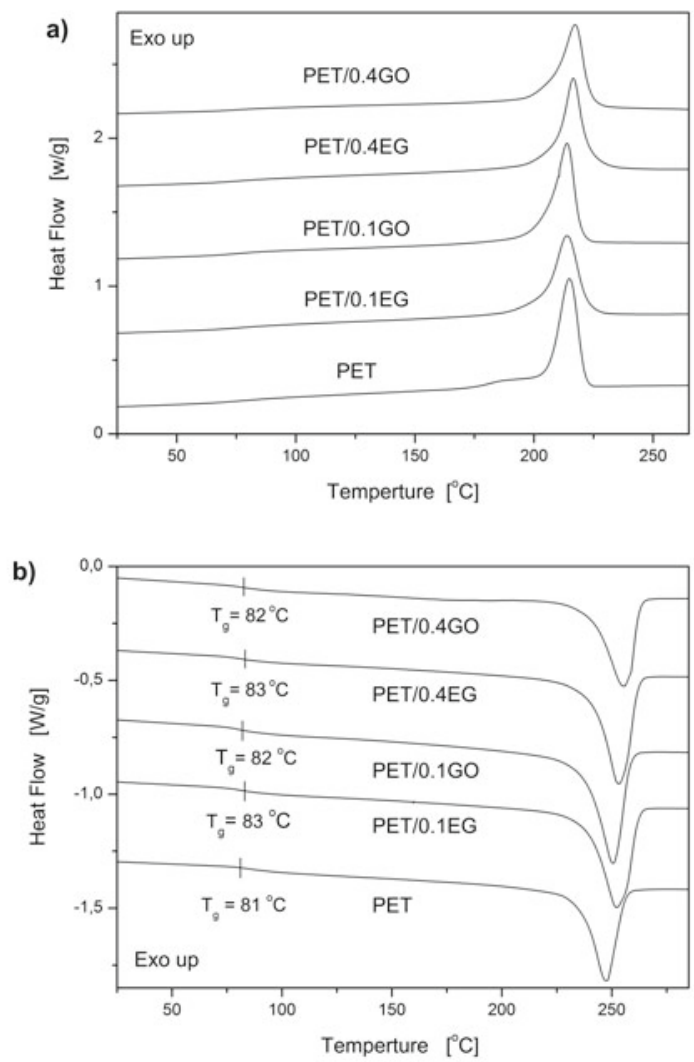

Figure 3. DSC thermograms for PET/EG and PET/GO nanocomposites with different nanofillers concentration during: a) cooling and b) 2nd heating 
Table 2. Transition temperatures and the degree of crystallinity of PET/EG and PET/GO nanocomposites

\begin{tabular}{|c|c|c|c|c|c|c|c|c|}
\hline Sample & $\begin{array}{c}\mathrm{T}_{\mathrm{g}} \\
{\left[{ }^{\circ} \mathrm{C}\right]}\end{array}$ & $\begin{array}{c}\Delta \mathrm{C}_{\mathrm{p}} \\
{\left[\mathrm{J} / \mathrm{g}^{\circ} \mathrm{C}\right]}\end{array}$ & $\begin{array}{c}\mathrm{T}_{\mathrm{m}} \\
{\left[{ }^{\circ} \mathrm{C}\right]}\end{array}$ & $\begin{array}{l}\Delta \mathrm{H}_{\mathrm{m}} \\
{[\mathrm{J} / \mathrm{g}]}\end{array}$ & $\begin{array}{c}\mathrm{T}_{\mathrm{c}} \\
{\left[{ }^{\circ} \mathrm{C}\right]}\end{array}$ & $\begin{array}{c}\Delta \mathrm{T} \\
{\left[{ }^{\circ} \mathrm{C}\right]}\end{array}$ & $\begin{array}{l}\Delta \mathrm{H}_{\mathrm{c}} \\
{[\mathrm{J} / \mathrm{g}]}\end{array}$ & $\begin{array}{c}x_{c} \\
{[\%]}\end{array}$ \\
\hline PET & 81 & 0.15 & 257 & 50.6 & 214 & 43 & 50.4 & 36.1 \\
\hline PET/0.1EG & 83 & 0.15 & 252 & 50.4 & 214 & 38 & 50.2 & 35.9 \\
\hline PET/0.4EG & 83 & 0.14 & 253 & 50.2 & 217 & 36 & 50.3 & 35.8 \\
\hline PET/0.1GO & 82 & 0.12 & 250 & 50.1 & 214 & 37 & 50.6 & 35.7 \\
\hline PET/0.4GO & 82 & 0.12 & 254 & 50.9 & 218 & 36 & 50.7 & 36.2 \\
\hline
\end{tabular}

$\mathrm{T}_{\mathrm{g}}-$ glass transition temperature; $\Delta \mathrm{c}_{\mathrm{p}}-$ heat capacity; $\mathrm{T}_{\mathrm{m}}-$ melting temperature; $\mathrm{T}_{\mathrm{c}}-$ crystallizing temperature; $\Delta \mathrm{T}=\mathrm{T}_{\mathrm{m}}-\mathrm{T}_{\mathrm{c}} ; \Delta \mathrm{H}_{\mathrm{m}}$, $\Delta \mathrm{H}_{\mathrm{c}}$ - enthalpy of melting and crystallization of polyester crystals, respectively, $x_{c}$ - degree of crystallinity.

has a significant effect on the non-isothermal crystallization kinetics of the PET nanocomposites in that the c-CNTs dispersed in the PET matrix can effectively act as strong nucleating agents and lead to the enhanced crystallization of the PET nanocomposites through heterogeneous nucleation ${ }^{28}$. Similar observations have been reported that the crystallization of CNT/polymer nanocomposites was accelerated by the presence of CNT through heterogeneous nucleation ${ }^{\mathbf{2 1}, 29-31}$. It has been also already published, that in PET/EG nanocomposites the addition of EG changed the crystallization mechanism, accelerated the crystallization rate, but decreased the crystallinity of the PET resin ${ }^{\mathbf{1 6}}$. The introduction of nanofiller produces a hindrance on the molecular chains movement, which will reduce the tendency for molecular chains to be crystallized, though the confined molecular chains may be well ordered in the lamellar space. Although, in our case only increase of crystallization rate was observed, but degree of crystallinity is not affected by the presence of the EG and GO.

\section{CONCLUSIONS}

The aim of this study was to investigate the influence of functionalized (GO) and non-functionalized (EG) carbon nanofillers on the synthesis process of PET based nanocomposites. In particular, the addition of nanofiller to the semicrystalline polymer matrix may influence on its crystallization. In our systems, increase of crystallization rate was observed, but degree of crystallinity is not affected by the presence of both: expanded graphite and graphene oxide. The crystallization traces indicate that GO worked as a more effective nucleation agent for the crystallization of PET. The high dispersion level of oxidized graphene sheets can be attributed to a strong interaction between functionalized groups on the surface of GO and the polar groups of PET (Fig. 1). It was characterized that disordered graphene sheets of EG and GO are well dispersed in the PET matrix without forming crystalline aggregates even at nanofiller content of 0.4 wt.\%. The influence on the intrinsic viscosity has been also observed. With the increasing content of EG and GO the decrease in [ $\eta]$ for PET matrix in nanocomposites was reported as a result of decreasing of PET polymer molecular weight. It is probably due to the influence of nanofiller on the second step of is situ polymerization. Polycondensation reaction with EG and GO becomes slower as evidenced by the slower increase in viscosity (measured by stirrer torque) of the system in the last stage of the synthesis. A slight reduce in the MVR with the increasing of GO content was observed, whereas a large increase from 72.8 (PET) to 118.9 $\mathrm{cm}^{3} / 10$ min (PET/0.4EG) might be a result in increasing of melt viscosity due to the polymer - graphene sheets interactions. Nanocomposites in comparison to the neat polymer have slightly higher density due to the presence of nanofiller with higher density.

\section{ACKNOWLEDGMENT}

The authors thank the financial support from MNT ERA-NET 2012 project (APGRAPHEL) for sponsored the study. Sandra Paszkiewicz and Małgorzata Nachman also thank for financial support from West Pomeranian University of Technology, Szczecin.

\section{LITERATURE CITED}

1. Paszkiewicz, S., Szymczyk, A., Špitalský, Z., Soccio, M., Mosnáček, J., Ezquerra, T.A. \& Rosłaniec, Z. (2012). Influence of EG on electrical conductivity of PET/EG nanocomposites prepared by in situ polymerization. J. Polym. Sci.: Part B: Polym. Phys. 50, 1645-1652. DOI:10.1002/polb.23176.

2. Paszkiewicz, S., Szymczyk, A., Špitalský, Z., Mosnáček, J. \& Rosłaniec, Z. (2012). Morphology and Thermal Properties of Expanded Graphite (EG)/Poly(ethylene terephthalate) (PET) Nanocomposites. CHEMIK 66(1), 21-30.

3. Mark, H.F., Bikales, N.M., Overberger, C.G. \& Menges, G. (1988). Encyclopedia of polymer science and engineering (2nd ed.). USA: Wiley Interscience.

4. Bhimaraj, P., Burris, D.L., Action, J., Sawyer, W.G., Toney, C.G., Siegel, R.W. \& Schadel, L.S. (2005). Effect of matrix morphology on the wear and friction behavior of alumina nanoparticle/poly(ethylene terephthalate) composites, Wear 258 (9), 1437-1443. DOI: 10.1016/j.wear.2004.09.077.

5. Krishnamoorti, R. \& Vaia, R.A. (2001). Polymer nanocomposites, synthesis, characterization and modeling. ACS symposium series, Washington DC, American Chemical Society.

6. Jain, S., Goossens, H., Duin, M. \& Lemstra, P. (2000). Effect of in situ prepared silica nano-particles on non-isothermal crystallization of polypropylene. Polym. 46, 8805-8818. DOI: 10.1016/j.polymer.2004.12.062.

7. Li, Z., Luo, G., Wie, F. \& Huang, Y. (2006). Microstructure of carbon nanotubes/PET conductive composites fibers and their properties. Comp. Sci. Techn. 66, 1022-1029. DOI: 10.1016/j.compscitech.2005.08.006.

8. Zheng, G., Wu, J., Wang, W. \& Pan, C. (2004). Characterizations of expanded graphite/polymer composites prepared by in situ polymerization Carbon 42, 2839-2847. DOI: 10.1016/j. carbon.2004.06.029.

9. Szymczyk, A., Paszkiewicz, S. \& Roslaniec, Z. (2013). Influence of intercalated organoclay on the phase structure and physical properties of PTT-PTMO block copolymers. Polym. Bull. 70, 1575-1590. DOI: 10.1007/s00289-012-0859-y.

10. Hernández, J.J., García-Gutiérrez, M.C., Nogales, A., Rueda, D.R., Kwiatkowska, M., Szymczyk, A., Roslaniec, Z., Concheso, A., Guinea, I. \& Ezquerra, T.A. (2009). Influence of preparation procedure on the conductivity and transparency of SWCNT-polymer nanocomposites. Comp. Sci. Tech. 69, 1867-1872. DOI: 10.1016/j.compscitech.2009.04.002.

11. Szymczyk, A., Roslaniec, Z., Zenker, M., García-Gutiérrez, M.C., Hernández, J.J., Rueda, D.R., Nogales, A. \& Ezquerra, T.A. (2011). Preparation and characterization of nanocomposites 
based on $\mathrm{COOH}$ functionalized multi-walled carbon nanotubes and on poly(trimethylene terephthalate). eXPR. Polym. Lett. 5(11), 977-995. DOI: 10.3144/expresspolymlett.2011.96.

12. Stankovich, S., Dikin, D.A., Dommett, G.H.B., Kohlhaas, K.M., Zimney, E.J., Stach, E.A., Piner, R.D, Nguyen, S.T. \& Ruoff, R.S. (2006). Graphene-based composite materials, Nature 442 (7100), 282-286. DOI:10.1038/nature04969.

13. Ramanathan, T., Abdala, A.A., Stankovich, S., Dikin, D.A., Herrera-Alonso, M., Piner, R.D., Adamson, D.H., Schniepp, H.C., Chen, X., Ruoff, R.S., Nguyen, S.T, Aksay, I.A., Prud'Homme, R.K. \& Brinson, L.C. (2008). Functionalized graphene sheets for polymer nanocomposites, Natur. Nanotech. 3(6), 327-331. DOI: 10.1038/nnano.2008.96.

14. Lee, C., Wei, X., Kysar, J.W. \& Hone, J. (2008). Measurement of the elastic properties and intrinsic strength of monolayer graphene, Science 321(5887), 385-388. DOI: 10.1126/ science.1157996.

15. Kim, I.H. \& Jeong, Y.G. (2010). Polylactide/exfoliated graphite nanocomposites with enhanced thermal stability, mechanical modulus, and electrical conductivity, J. Polym. Sci. Part B: Polym. Phys. 48(8), 850-858. DOI: 10.1002/polb.21956.

16. Zhang, M., Li, D.J., Wu, D.F., Yan, C.H., Lu, P. \& Qiu, G.M. (2008). Poly(ethylene terephthalate)/expanded graphite conductive composites: structure, properties, and transport behavior, J. Appl. Polym. Sci. 108 (3), 1482-1489. DOI: 10.1002/ app. 27745 .

17. Zhang, H.B., Zheng, W.G., Yan, Q., Yang, Y., Wang, J.W., Lu, Z.H., Ji, G.Y. \& Yu, Z.Z. (2010). Electrically conductive polyethylene terephthalate/graphene nanocomposites prepared by melt compounding. Polym. 51(5), 1191-1196. DOI: 10.1016/j. polymer.2010.01.027.

18. Szymczyk, A. (2009). Structure and properties of new polyester elastomers composed of poly(trimethylene terephthalate) and poly(ethylene oxide). Eur. Polym. J. 45, 2653-2664. DOI: 10.1016/j.eurpolymj.2009.05.032.

19. Anand, K.A., Agarwal, U.S. \& Joseph, R. (2007). Carbon nanotubes-reinforced PET nanocomposite by meltcompounding. J. Appl. Polym. Sci. 104(5), 3090-3095. DOI :10.1002/app.25674.

20. Wunderlich, B. (1980). Macromolecular Physics (3rd Ed.). New York, USA: Academic Press.

21. Kim, J.Y., Han, S.I. \& Hong, S. (2008). Effect of Modified Carbon Nanotube on the Properties of Aromatic Polyester Nanocomposites. Polym. 49, 3335-3345. DOI:10.1016/j. polymer.2008.05.024.

22. Spiros, T., Drakonakis, V., Mouzakis, D.E., Fischer, D. \& Gregoriou, V.G. (2006). Effect of Carboxy-Functionalized Multiwall Nanotubes (MWNT-COOH) on the Crystallization and Chain Conformations of Poly(ethylene terephthalate) PET in PET-MWNT Nanocomposites. Macromol. 39, 9150-9156. DOI: $10.1021 / \mathrm{ma} 0613584$.

23. Godovsky, Y.K., Slonimsky, G.L. \& Garbar, N.M. (1972). Effect of molecular weight on the crystallization and morphology of poly(ethylene oxide) fractions. J. Polym. Sci.: Part C 38(1), 1-21. DOI: $10.1002 /$ polc.5070380103.

24. Lopez, L.C. \& Wilkes, G.L. (1988). Crystallization kinetics of poly(p-phenylene sulphide): effect of molecular weight. Polym. 29, 106-113. DOI: 10.1016/0032-3861(88)90207-8.

25. Krikorian, V. \& Kochan, D.J. (2005). Crystallization Behavior of Poly(l-lactic acid) Nanocomposites: Nucleation and Growth Probed by Infrared Spectroscopy. Macromol. 38(15), 6520-6527. DOI: 10.1021/ma050739z.

26. Hu, X., An, H., Li, Z. \&Yang, L. (2009). Origin of Carbon Nanotubes Induced Poly(l-Lactide) Crystallization: Surface Induced Conformational Order. Macromol. 42(8), 3215-3218. DOI: $10.1021 / \mathrm{ma} 802758 \mathrm{k}$.

27. Zhang, J., Duan, Y., Sato, H., Tsuji, H., Noda, I., Yan, S.K. \& Ozaki, Y. (2005). Crystal Modifications and Thermal Behavior of Poly (L -lactic acid) Revealed by Infrared Spectroscopy. Macromol. 38(19), 8012-8021. DOI: 10.1021/ma051232r.
28 Kim, J.Y. \& Kim, S.H. (2012). Nanocomposites - New Trends and Developments, InTech, Retrieved October 2012, from InTech DTP team. http://www.intechopen.com/books/nanocomposites-new-trends-anddevelopments. DOI: 10.5772/50413.

29. Kim, J.Y., Han, S.I. \& Kim, S.H. (2007). Crystallization Behavior and Mechanical Properties of Poly(ethylene-2,6naphthalate)/Multiwall Carbon Nanotube Nanocomposites. Polym. Eng. Sci. 47, 1715-1723. DOI:10.1002/pen.20789.

30. Kim, J.Y. (2009). The Effect of Carbon Nanotube on the Physical Properties of Poly(butylene terephthalate) Nanocomposite by Simple Melt Blending. J. Appl. Polym. Sci.112(5), 2589-2600. DOI: 10.1002/app.29560.

31. Kim, J.Y., Ki, D.K. \& Kim, S.H. (2009). Effect of Modified Carbon Nanotube on Physical Properties of Thermotropic Liquid Crystal Polyester Nanocomposites. Eur. Polym. J. 45(2), 316-324. DOI: 10.1016/j.eurpolymj.2008.10.043. 